\title{
Pronóstico de ventas de las empresas del sector alimentos: una aplicación de redes neuronales*
}

\author{
Recibido: 23 de julio de 2019 • Aprobado: 17 de octubre de 2019 \\ https://doi.org/10.22395/seec.v22n52a7
}

\author{
Arturo Morales Castro** \\ Eliseo Ramírez Reyes ${ }^{* * *}$ \\ Gustavo Rodríguez Albor ${ }^{* * *}$
}

\section{RESUMEN}

El objetivo de esta investigación es pronosticar las ventas de las siguientes empresas: Industrias Bachoco, Grupo Bafar, Grupo Bimbo, Gruma, Grupo Herdez, Grupo Lala y Grupo Industrial Maseca del periodo 2006 al 2015, a través de modelos lineales (regresión lineal) y no lineales (redes neuronales artificiales, tablas de decisión, árbol de decisión y procesos gaussianos) para medir el desempeño de cada uno de estos modelos y seleccionar para cada empresa aquel modelo que presente un mayor ajuste a los datos históricos. Como resultado, en el periodo de 2006-2015 los modelos de regresión lineal múltiple presentaron un mejor desempeño en determinar las ventas de Bachoco, Bafar, Herdez, Lala y Maseca con más de 90 \% de recuperación de los datos dentro de este periodo.

\section{PALABRAS CLAVE}

Pronóstico de ventas; variables económico-financieras; minería de datos; regresión lineal; empresas de alimentos.

\section{CLASIFICACIÓN JEL}

E31, C45, C55.

\section{CONTENIDO}

Introducción; 1. Integración del pronóstico dentro de las actividades administrativas; 2. Pronósticos con redes neuronales artificiales; 3. Metodología; 4. Resultados; 5. Conclusiones; Bibliografía.

* Este artículo es el resultado de una investigación de la Maestría en Finanzas de la Universidad Nacional Autónoma de México (2017), titulado Pronóstico de ventas de las empresas del sector alimentos: una aplicación de redes neuronales y minería de datos.

* Economista, Universidad Nacional Autónoma de México, Ciudad de México, México. Magíster en Finanzas, Universidad Nacional Autónoma de México, Ciudad de México, México. Doctor en Administración, Universidad Nacional Autónoma de México, Ciudad de México, México. Profesor e investigador, Facultad de Contaduría y Administración, Universidad Nacional Autónoma de México, Ciudad de México, México. Integrante del Sistema Nacional de Investigadores con el nombramiento de Investigador Nacional Nivel I del Conacyt. Correo electrónico: amorales@fca.unam.mx

... Ingeniero químico y magíster en Finanzas, Universidad Nacional Autónoma de México, Ciudad de México, México. Estudiante de Doctorado en Administración, Universidad Nacional Autónoma de México, Ciudad de México, México. Correo electrónico: eliseod@comunidad.unam.mx

..** Doctor en Ciencias Sociales, Universidad del Norte, Barranquilla, Colombia. Profesor e investigador Facultad de Ciencias Administrativas, Económicas y Contables, Universidad Autónoma del Caribe, Barranquilla, Colombia. Correo electrónico: gustavo.rodriguez51@uac.edu.co 


\title{
SALES FORECAST OF COMPANIES IN THEFOOD SECTOR: ANEURAL NETWORKS APPLIANCE
}

\begin{abstract}
The goal of this research is to forecast the sales of the following companies: Industrias Bachoco, Grupo Bafar, Grupo Bimbo, Gruma, Grupo Herdez, Grupo Lala y Grupo Industrial Maseca in the period 2006-2015 through a linear model (linear regression) and a non-linear model (artificial neural networks, decision tables, decision tress and gaussian process) for measuring the performance of each of these models and selecting for each company the model which adjusts more precisely to the historical data. As a result, in the 2006-2015 period the multiple linear regression models show a better performance in determining the sales of Bachoco, Bafar, Herdez, Lala and Maseca with more than $90 \%$ of the data recovered within this period.
\end{abstract}

\section{KEY WORDS}

Sales forecast; economic-financial variables; data mining; linear regression; food companies .

JEL CODE

E31, C45, C55.

\section{CONTENTS}

Introduction; 1. Integration of the forecast within the management activities; 2. Forecasts with artificial neural networks; 3. Methodology; 4. Results; 5. Conclusions; Bibliography.

\section{PREVISÃO DE VENDAS DAS EMPRESAS DO SETOR ALIMENTOS: UMA APLICAÇÃO DE REDES NEURAIS}

\section{RESUMO}

O objetivo desta pesquisa é predizer as vendas das seguintes empresas: Industrias Bachoco, Grupo Bafar, Grupo Bimbo, Gruma, Grupo Herdez, Grupo Lala e Grupo Industrial Maseca de 2006 a 2015, por meio de modelos lineares (regressão linear) e não lineares (redes neurais artificiais, tabelas de decisão, árvore de decisão e processos gaussianos) para medir o desempenho de cada um desses modelos e escolher, para cada empresa, o modelo que apresentar um maior ajuste aos dados históricos. Como resultado, no período 2006-2015, os modelos de regressão linear múltipla apresentam um melhor desempenho em determinar as vendas de Bachoco, Bafar, Herdez, Lala e Maseca com mais de $90 \%$ de recuperação dos dados dentro desse período.

\section{PALAVRAS-CHAVE}

Previsão de vendas; variáveis econômico-financeiras; mineração de dados; regressão linear; empresas de alimentos.

\section{CLASSIFICAÇÃO JEL}

$$
\text { E31, C45, C55. }
$$

\section{CONTEÚDO}

Introdução; 1. Integração da previsão dentro das atividades administrativas; 2. Prognósticos com redes neurais artificiais; 3. Metodologia; 4. Resultados; 5 . Conclusões; Bibliografia. 


\section{INTRODUCCIÓN}

En esta investigación se presenta una propuesta metodológica para determinar el comportamiento de las ventas de las siguientes empresas del sector alimentos: Industrias Bachoco, Grupo Bafar, Grupo Bimbo, Gruma, Grupo Herdez, Grupo Lala y Grupo Industrial Maseca. Se comparan modelos lineales y no lineales para determinar aquellos que presenten un mayor ajuste a los datos históricos.

Lo que motiva esta investigación es realizar modelos, tanto lineales como no lineales, que permitan encontrar la relación causal entre las variables económicofinancieras propuestas: salario mínimo, población total en México, porcentaje de población urbana, cinco razones financieras, tipo de cambio fix y tres índices de Standard \& Poor's (SEP).

En esta investigación se usarán los términos metodología, técnica y modelo, de acuerdo con el tema de minería de datos. La metodología se refiere a la familia de algoritmos de minería de datos que comparten un fundamento teórico. Como ejemplo de familias se encuentran: probabilísticos, tablas de decisión, árboles de decisión y redes neuronales y meta clasificadores.

En minería de datos, la técnica es como resuelve el fundamento (metodología) un problema en la práctica. Es la herramienta utilizada para resolver un problema de predicción o de clasificación de patrones. Como ejemplo, de la familia de redes neuronales, la técnica utilizada en esta investigación es perceptrón multicapa.

El modelo de minería de datos es la asociación propuesta de variables dependientes e independientes mediante una expresión matemática. Como ejemplo, es la propuesta de esta investigación de asociar trece variables económico-financieras al pronóstico de ventas de siete empresas del sector alimentos.

Los modelos de pronósticos de ventas han presentado un avance desde los modelos estadísticos tradicionales como la regresión lineal simple y el modelo ARIMA hasta los modelos avanzados como lo son las redes neuronales artificiales (RNA) como lo menciona Gupta y Kumar (2013).

Se ha comprobado mediante investigaciones acerca de los avances en las técnicas del pronóstico de ventas, que las redes neuronales artificiales (RNA) presentan una mayor precisión en comparación con algunos métodos como el de regresión lineal y el de ARIMA. Sin embargo, no se han aprovechado las características que las RNA presentan como la asociación, evaluación y reconocimiento de patrones para estimar el impacto que tendrían algunas variables asociadas a las ventas de una compañía. 
Esta investigación se enfocará en un grupo de empresas que cotizan en la Bolsa Mexicana de Valores (BMV) que pertenecen al sector alimentos para realizar el pronóstico de ventas. En esta investigación se decidió estudiar a las empresas que pertenecen al sector de alimentos. Se eligió este sector porque presenta las siguientes características: el sector alimentario es el que tiene una mayor participación en el IPC con respecto a las 37 empresas que integran este índice (como se muestra en la tabla 1). El IPC en este periodo cuenta con 37 emisoras debido a la escisión de Sites (de América Móvil) y la generación de una nueva empresa y emisora (Lacomer) con las tiendas restantes de la Comercial Mexicana que no vendió a Soriana.

Tabla 1. Participación en el índice de precios y cotizaciones

\begin{tabular}{llll}
\hline & Nombre & \multicolumn{1}{c}{ Sector economática } & Participación en el índice \\
\hline 1 & 7 ítems & Alimentos y bebidas & Suma \\
\hline 2 & 5 ítems & Comercio & $22,7 \%$ \\
\hline 3 & 5 ítems & Finanzas y seguros & $12,1 \%$ \\
\hline 4 & 4 ítems & Transporte y servicios & $14,2 \%$ \\
\hline 5 & 3 ítems & Construcción & $6,5 \%$ \\
\hline 6 & 3 ítems & Telecomunicación & $2,2 \%$ \\
\hline 7 & 2 ítems & Otros & $18,4 \%$ \\
\hline 8 & 2 ítems & Minería & $1,3 \%$ \\
\hline 9 & 2 ítems & Química & $8,5 \%$ \\
\hline 10 & 1 ítem & Siderúrgica y metalúrgica & $1,9 \%$ \\
\hline 11 & 1 ítem & Minerales no metales & $3,7 \%$ \\
\hline 12 & 1 ítem & Energía eléctrica & $7,4 \%$ \\
\hline 13 & 1 ítem & Vehículos y pieza & $0,6 \%$ \\
\hline
\end{tabular}

Fuente: Economática (2016).

El sector alimentos representa un 22,708 \% del IPC, lo que implica que al estudiar este sector se estaría representando casi una cuarta parte del desempeño bursátil en México.

Este estudio se divide en cinco apartados: i) introducción, ii) marco teórico de los pronósticos en los negocios y los pronósticos con redes neuronales artificiales, iii) descripción de la metodología de la investigación, iv) se implementan los modelos de regresión lineal, redes neuronales artificiales, tablas de decisión, árbol de decisión y procesos gaussianos que muestran la relación entre las variables económicas seleccionadas y los ingresos de las empresas de alimentos en México, v) conclusiones. 


\section{INTEGRACIÓN DEL PRONÓSTICO DENTRO DE LAS ACTIVIDADES ADMINISTRATIVAS}

Los pronósticos han tomado una mayor importancia a partir de los cambios macroeconómicos y las crisis financieras que han surgido en los últimos años y es por esto que forman parte de la planeación financiera, de la producción y de otras áreas corporativas de acuerdo con Makridakis y Wheelwringhts (1977).

Los pronósticos de ventas no se pueden ver de manera aislada con respecto a la toma de decisiones gerenciales. Jain (2002) explica que los pronósticos deben tener el respaldo del gerente, pues es quien asigna recursos para comenzar y dar seguimiento al pronóstico.

Además, para realizar un pronóstico exitoso se requiere la participación de las áreas de producción, mercadotecnia, ventas y finanzas para que cada una aporte los elementos de entrada del modelo del pronóstico de ventas para reflejar los elementos internos y externos de la empresa (Jain, 2002).

\subsection{Tipos de pronósticos}

Como se muestra en la tabla 2, los métodos de pronósticos están divididos en dos categorías: los métodos cualitativos y los métodos cuantitativos en los que se encuentran las series de tiempo y el método causal.

Tabla 2. Ventajas y desventajas de los métodos de pronósticos

\begin{tabular}{|c|c|c|}
\hline Método & Ventajas & Desventajas \\
\hline $\begin{array}{l}\text { Cualitativo } \\
\text { (juicio) }\end{array}$ & $\begin{array}{l}\text { Provee pronósticos muy precisos. } \\
\text { Tiene bajo costo de desarrollo. } \\
\text { Los ejecutivos tienen una sólida } \\
\text { comprensión de los factores que } \\
\text { afectan a las ventas haciendo que el } \\
\text { pronóstico se desarrolle más rápido. }\end{array}$ & $\begin{array}{l}\text { No hay una precisión constante a través } \\
\text { del tiempo debido a la naturaleza de su } \\
\text { desarrollo. } \\
\text { Algunos ejecutivos no comprenden la si- } \\
\text { tuación de ventas de la empresa cuando se } \\
\text { maneja una gran diversidad de productos. }\end{array}$ \\
\hline $\begin{array}{l}\text { Series de } \\
\text { tiempo }\end{array}$ & $\begin{array}{l}\text { Estos métodos se adaptan a las } \\
\text { situaciones en donde se necesita un } \\
\text { pronóstico de ventas para una gran } \\
\text { cantidad de productos. } \\
\text { Pueden suavizar pequeñas fluctua- } \\
\text { ciones aleatorias. }\end{array}$ & $\begin{array}{l}\text { Requieren una gran cantidad de datos } \\
\text { históricos. } \\
\text { Ajustan pequeños cambios en las ventas. } \\
\text { A largo plazo el pronóstico tiende a presentar } \\
\text { errores grandes debido a las grandes fluctua- } \\
\text { ciones en los datos actuales. }\end{array}$ \\
\hline Causales & $\begin{array}{l}\text { Están disponibles en la mayoría de } \\
\text { los paquetes de software. } \\
\text { No son caros para correr en las } \\
\text { computadoras. } \\
\text { Son precisos a corto y mediano plazo. }\end{array}$ & $\begin{array}{l}\text { La precisión del pronóstico depende de la re- } \\
\text { lación consistente de variables dependientes } \\
\text { e independientes. } \\
\text { La falta de comprensión por los gerentes, que } \\
\text { los ven como una caja negra. }\end{array}$ \\
\hline
\end{tabular}

Fuente: Chase (1997, p. 23). 
Chase (1997), retomando los diferentes métodos de pronósticos comparó las ventajas y desventajas de los métodos de pronósticos.

\subsection{Selección de las variables clave}

Se puede considerar un número de variables para las cuales hay causas específicas o determinantes que pueden afectar las operaciones y la rentabilidad de un negocio que siguen una tendencia. Una tendencia es la dirección persistente en la cual algo se mueve en el corto, mediano o largo plazo. Identificar esta tendencia les permite a los administradores mejorar la planeación al conocer las necesidades futuras, de acuerdo con Wienclaw (2015).

Van Tassel (1967) encuentra que el consumo de alimentos en familias que trabajan en actividades agrícolas es menos elástico en relación con el ingreso en comparación con las familias que trabajan en actividades no agrícolas. Además de que los patrones de consumo de productos alimenticios varían entre estos dos grupos de personas.

Ohidul (2005) establece que el incremento en la demanda de algún bien de consumo depende de algunos factores como:

- El crecimiento en el ingreso.

- Cambios en los precios.

- Incremento neto en el crecimiento de la población.

- Cambios en los patrones de consumo (cambios en gustos y preferencias).

- Cambios en la composición de la familia.

- Cambios en la distribución del ingreso.

Para Lundberg y Lundberg (2012) las familias de altos ingresos tienden a gastar una mayor participación de su incremento de ingresos en comida en comparación con las familias de bajos ingresos. Los alimentos son un bien normal y los grupos de altos ingresos pueden cambiar a los alimentos más exclusivos cuando reciben un incremento en sus ingresos.

La demanda incrementa con el número de tarjetas de crédito que las familias poseen sugiriendo una diferencia en el comportamiento de compra entre los usuarios de las tarjetas de crédito y los que son renuentes a comprar a crédito, de acuerdo con Lundberg y Lundberg (2012).

Juárez (2007) en la investigación Análisis del efecto del tipo de cambio en la estructura financiera de las empresas que cotizan en la Bolsa Mexicana de Valores: sector alimentos, bebidas 
y tabaco, identifica las fluctuaciones en el tipo de cambio como variable clave en el cambio de la estructura financiera de las empresas del sector alimentos a través de seis razones financieras que se muestran a continuación:

- Pasivo total/activo total.

- Pasivo total/capital contable.

- Pasivo en moneda extranjera/pasivo total.

- Pasivo a largo plazo/activo fijo.

- Resultado de operación/intereses pagados.

- Ventas netas/pasivo total.

Aun cuando no es la finalidad de esta investigación, se validan las conclusiones de la tesis de Juárez con estas razones financieras.

\subsection{Evaluación de los pronósticos}

Es fundamental evaluar la utilidad de una gama de modelos de pronósticos. García et al. (2009) considera los siguientes aspectos para la evaluación de un modelo:

\section{Medidas de la exactitud del pronóstico}

La medida más adoptada en la raíz cuadrada del error medio (RCEM)

$$
R C M E=\sqrt{\frac{1}{m} \sum_{t=1}^{m} e_{t}^{2}}
$$

Una ventaja de esta medición es que la pérdida asociada con un error aumenta en proporción con el cuadrado de un error. Una desventaja de la RCEM es que es una medición que depende de las unidades de medida, para evitar esto se puede hacer adimensional esta ecuación a través de la raíz cuadrada relativa del error medio (RCREM)

$$
R C M E=\sqrt{\frac{1}{m} \sum_{t=1}^{m} \frac{e_{t}^{2}}{z_{t}}}
$$

Donde zt es la serie reportada. Lo que presenta una desventaja cuando su valor se aproxime a cero.

La tercera medida de exactitud es el error medio absoluto (EMA)

$$
E M A=\frac{1}{m} \sum_{t=1}^{m} e_{t}[3]
$$


Es utilizada cuando la función de pérdida es lineal y simétrica. El error porcentual medio absoluto (EPMA) es la medida relativa del EMA y presenta las mismas desventajas que el RCREM.

$$
E P M A=\frac{1}{m} \sum_{t=1}^{m} \frac{e_{t}}{z_{t}}
$$

\section{Coeficiente U de Theil}

El coeficiente $U$ de Theil es una medida de la exactitud del pronóstico. Donde et representa los errores del pronóstico. La U es una comparación de la suma de los cuadrados de los pronósticos más los correspondientes a un modelo de caminata aleatoria.

\section{PRONÓSTICOS CON REDES NEURONALES ARTIFICIALES}

Las redes neuronales artificiales (RNA) se han utilizado en diferentes campos de investigación, en este caso veremos los relacionados con el pronóstico de ventas.

A continuación, se muestran las principales investigaciones realizadas con redes neuronales en el tema de pronóstico de ventas. Las principales aportaciones de estas investigaciones son:

- Las redes neuronales artificiales (RNA) presentan un mejor desempeño en pronósticos no lineales, a través del patrón de reconocimiento.

- En los pronósticos de series de tiempo las redes neuronales artificiales presentan una mayor precisión que los métodos estadísticos tradicionales.

\subsection{Ventajas y limitaciones de las redes neuronales artificiales}

La construcción de un modelo aplicado a un pronóstico específico basado en redes neuronales artificiales puede llegar a ser exitoso si se tiene en cuenta el proceso de construcción del modelo. El software por sí solo no puede dar una solución satisfactoria, de acuerdo con Zhang (2004).

Las decisiones más importantes del pronosticador son: la preparación de datos, la selección de las variables de entrada, la elección de un tipo de arquitectura, los algoritmos de entrenamiento y los modelos de validación, evaluación y selección, de acuerdo con Zhang (2004).

Las redes neuronales artificiales son técnicas del manejo de datos por lo que la confiabilidad de sus modelos depende de una gran extensión en la calidad de los datos. 
Hay diferentes temas prácticos alrededor de los requerimientos para un modelo de RNA. El primero es el tamaño de la muestra para construir una red neuronal. Una muestra de mayor tamaño provee una mejor oportunidad a las redes neuronales para aproximar la estructura de los datos. Por lo tanto, una muestra grande es deseable para un modelaje no lineal.

El segundo tema es la división de datos en datos dentro de la muestra y fuera de la muestra. Los datos dentro de la muestra sirven para validar y entrenar la muestra. Los datos fuera de la muestra se usan para evaluar la predicción del modelo.

Es importante para una red neuronal determinar las variables de entrada apropiadas para capturar la relación esencial que puede ser usada para un pronóstico exitoso. El número y el tipo de variables usadas en la capa de entrada de una red neuronal afectan el comportamiento de una red neuronal en los datos dentro y fuera de la muestra.

\section{METODOLOGÍA}

\subsection{Alcance de la investigación}

La presente investigación abordará el tema de pronóstico de ventas con un enfoque cuantitativo, es correlacional porque establece la relación entre variables dependientes e independientes asociadas a las ventas de las empresas del sector alimentos mediante el uso de redes neuronales artificiales (RNA) y técnicas de minería de datos durante un periodo de diez años generando un estudio longitudinal.

Las variables que se considerarán son: ventas netas, tres índices de empresas del sector alimentos de SEP, el porcentaje de población urbana, la población total en México, tipo de cambio, salario mínimo y cinco razones financieras. Se eligieron los índices de S\&P que reflejan el comportamiento de la industria alimenticia a nivel internacional.

Esta investigación no es experimental, pues no se puede llevar a cabo la manipulación, medición ni control experimental de las variables seleccionadas para el pronóstico de ventas, pero es histórica ya que se usarán datos históricos de las principales variables que afectan a las ventas de las empresas del sector alimentos que se aplicarán en el modelo de ventas.

\subsection{Diseño de la investigación}

Para la construcción de los modelos lineales y no lineales se utilizarán los datos que correspondan a los estados financieros de las empresas del sector alimentos 
los cuales se tomarán de Economática. Los índices de SEP se tomarán de: www. spdji.com. Los datos económicos provendrán del Inegi.

Una vez recaba la información, se definirá un periodo de diez años para diseñar diferentes arquitecturas de RNA hasta encontrar aquella que presente un mayor porcentaje de recuperación en la fase de prueba y se tomarán los impactos de variables de dicha red para obtener aquellas variables independientes (económicofinancieras) que tengan un mayor impacto en las ventas de las empresas analizadas.

Una vez definidas las variables de estudio, se construirá un modelo econométrico y se aplicarán pruebas de hipótesis para validar que las variables seleccionadas explican las ventas de la empresa. Después se probarán diferentes modelos de clasificación de minería de datos para seleccionar aquellos que muestren mayor ajuste a los datos de la muestra.

Se probarán distintos modelos de pronóstico lineales y no lineales para encontrar aquel que se ajuste con mayor precisión a los datos de la muestra. Al final, se realizará el pronóstico a tres trimestres de las empresas del sector alimentos con los datos históricos a diez años de todas las variables.

Una vez que se haya aplicado cada uno de los modelos propuestos, se compararán los resultados obtenidos. También se analizarán los patrones de datos encontrados para dar una mayor interpretación al pronóstico de ventas realizado.

\section{RESULTADOS}

A continuación, se presentan los resultados del pronóstico de ventas de las siguientes empresas del sector alimentos.

En la intención de pronosticar el nivel de las ventas de Bachoco, y con un enfoque ecléctico, primero se identificaron las variables económico-financieras que según la teoría pudieran explicar el incremento de sus ventas.

Se refiere la literatura a algunas investigaciones que dan cuenta de estas variables, por ejemplo, Morales y García (2016) clasifican y predicen las empresas exitosas y no exitosas del sector comercial de la BMV y utilizan tres razones financieras (VN/ PT, VN/AF y VN/AT) con un $54 \%$ de sensibilidad en la determinación del éxito o no éxito en el sector comercial de la BMV. Se encuentra que esta investigación está relacionada con las ventas de las empresas.

Ohidul (2005), afirma y encuentra en la investigación Income Elasticity and Economic Development Methods and Applications que el incremento en la demanda de algún bien 
de consumo depende de algunos factores como: el crecimiento en el ingreso, cambios en los precios, incremento neto en el crecimiento de la población, cambios en los patrones de consumo (cambios en gustos y preferencias) y cambios en la composición de la familia, lo cual se relaciona con el pronóstico de ventas.

A partir de los estudios mencionados se escogieron cinco variables económicofinancieras (salario mínimo, tipo de cambio (TC), población total en México (PoblaciónT) y concentración de población urbana (CPU)), tres índices financieros del sector alimentos (SEP Global BMI Consumer Staples (SP1), SEP Commodity Producers Agribusiness (SP2) y SEP Composite 1500 Consumer Staples (SP3)) y cinco razones financieras (PT/AT, PT/CC, PL/AF, ROp/GF y VN/PT).

- El crecimiento en el ingreso (salario mínimo).

- Población total en México.

- Porcentaje de población urbana.

- Pasivo total/activo total (razón financiera 1).

- Pasivo total/capital contable (razón financiera 2).

- Pasivo a largo plazo/activo fijo (razón financiera 3).

- Resultado de operación/intereses pagados (razón financiera 4).

- Ventas netas/pasivo total (razón financiera 5).

- Tipo de cambio fix.

- Índices SEP (SEP Global BMI Consumer Staples, SEP Commodity Producers Agribusiness y SEP Composite 1500 Consumer Staples).

Luego de identificar dichas variables y probar su relación con las ventas, se plantearon cuatro arquitecturas de redes neuronales artificiales (RNA) que permitieran ver el impacto de cada variable en las ventas. Para cada arquitectura se identificaron las variables más relevantes en el reporte de impacto de variables.

Al probar las diferentes arquitecturas de RNA fue posible identificar la ponderación de cada variable seleccionada en la predicción de las ventas y con ello discriminar las que no.

En la intención de contrastar un modelo no lineal como el de RNA y uno lineal como el de regresión múltiple y ver el desempeño de ambos en el comportamiento 
y pronóstico de las ventas de la empresa, se formuló un modelo econométrico con las variables que se utilizaron en la RNA y que demostraron explicar las ventas a través de las pruebas de hipótesis correspondientes.

Se encontró que algunas variables en el modelo lineal son significativas y otras no. A través de las pruebas de autocorrelación, heteroscedasticidad y multicolinealidad se probaron las variables que se ingresaron al modelo y se descartaron aquellas que no cumplieron con los supuestos del modelo clásico de regresión lineal.

Con las cinco variables económico-financieras (salario mínimo, tipo de cambio (TC), población total en México (PoblaciónT) y concentración de población urbana (CPU)), tres índices financieros del sector alimentos (SEP Global BMI Consumer Staples (SP1), SEP Commodity Producers Agribusiness (SP2) y SEP Composite 1500 Consumer Staples (SP3)) y cinco razones financieras (PT/AT, PT/CC, PL/AF, ROp/GF y VN/PT) se aplicaron tres técnicas de minería de datos (tabla de decisiones, árbol de decisiones y proceso gaussiano) en la intensión de contrastar los modelos anteriores.

Se midió el desempeño de cada técnica utilizada a través del porcentaje de recuperación de datos, el cual sirve como referencia para medir la cantidad de datos que el modelo pudo recuperar en la etapa de entrenamiento y prueba.

A través de las técnicas de minería de datos (RNA multicapa, tabla de decisiones, árbol de decisiones y proceso gaussiano) y el modelo de regresión lineal se encontró que las variables significativas en el comportamiento y pronóstico de las ventas de la empresa Bachoco son: concentración de población urbana (CPU) con población total en México y la razón financiera 1 (pasivo total/activo total).

Con esta investigación se valida el principio de la razón financiera 1 (pasivo total/ activo total). Esta razón de deuda total mide el grado de endeudamiento que tiene una empresa para financiar el conjunto de bienes y derechos que son propiedad de la empresa y que le sirven para generar ventas y utilidades.

A mayor grado de apalancamiento financiero aumentarían las ventas ya que se supondría que la inversión en activos fijos e inventarios crece y por tanto la capacidad instalada de la empresa lo que le facilita aumentar el volumen de ventas.

También se valida la teoría de la demanda del consumidor que define que el comportamiento del consumidor es racional con relación a los precios. La demanda representa la cantidad de producto que el consumidor desea comprar en función de la utilidad, los precios y la población que se miden con las variables: precio del huevo, concentración de población urbana (CPU) y la población total en México. 
Se compararon tanto el modelo de RNA, regresión lineal, tabla de decisiones, árbol de decisiones y proceso gaussiano a través del error absoluto medio para comparar el desempeño de cada una de las técnicas.

Tabla 3. Pronóstico de ventas: precisión entre modelos de minería de datos

\begin{tabular}{lccccc}
\hline \multicolumn{5}{c}{ Modelos de minería de datos } \\
\hline Compañía & RNA (multicapa) & Regresión lineal & $\begin{array}{c}\text { Tabla de } \\
\text { decisiones }\end{array}$ & $\begin{array}{c}\text { Árbol de } \\
\text { decisiones }\end{array}$ & $\begin{array}{c}\text { Proceso } \\
\text { gaussiano }\end{array}$ \\
\hline Bachoco & $94,1 \%$ & $97,7 \%$ & $99,0 \%$ & $98,9 \%$ & $74,5 \%$ \\
\hline Bafar & $94,6 \%$ & $96,8 \%$ & $98,2 \%$ & $98,2 \%$ & $88,9 \%$ \\
\hline Bimbo & $89,1 \%$ & $91,2 \%$ & $92,4 \%$ & $92,4 \%$ & $81,3 \%$ \\
\hline Gruma & $98,0 \%$ & $92,9 \%$ & $99,4 \%$ & $99,4 \%$ & $93,6 \%$ \\
\hline Herdez & $86,5 \%$ & $96,3 \%$ & $96,8 \%$ & $96,8 \%$ & $39,6 \%$ \\
\hline Lala & $94,5 \%$ & $97,7 \%$ & $91,5 \%$ & $91,5 \%$ & $90,8 \%$ \\
\hline Maseca & $90,7 \%$ & $97,4 \%$ & $98,9 \%$ & $99,2 \%$ & $86,4 \%$ \\
\hline
\end{tabular}

Fuente: elaboración con datos de Economática empleando el software SPSS v.23 y WEKA v3.8.

\section{CONCLUSIONES}

Al inicio de esta investigación el objetivo principal era construir una red neuronal artificial (RNA) que pronosticara con mayor precisión las ventas de siete empresas del sector alimentos (Bachoco, Bafar, Bimbo, Gruma, Herdez, Lala y Maseca).

La hipótesis principal planteada es que las RNA pronostican de manera más precisa en comparación con las técnicas de regresión lineal múltiple y las tres técnicas de minería de datos (tabla de decisiones, árbol de decisiones y proceso gaussiano).

Al emplear las técnicas de pronóstico se encontró que el objetivo principal no se cumple en las siete empresas del sector alimentos porque las técnicas de tabla de decisiones y árbol de decisiones tuvieron un mejor desempeño en el pronóstico de ventas de Bachoco, Bafar, Bimbo, Gruma, Herdez y Maseca. Sin embargo, en el caso del pronóstico de ventas de Gruma las RNA tuvieron un mejor desempeño en comparación con la regresión lineal múltiple.

El caso del pronóstico de ventas de Lala fue el único en donde la técnica de regresión lineal múltiple tuvo el mejor desempeño en comparación con RNA y las técnicas de tabla de decisiones, árbol de decisiones y proceso gaussiano. 
Los métodos de redes neuronales artificiales y minería de datos consideran las variables de entrada y ponderan el peso que cada una de ellas tiene sobre las ventas. Mientras que los modelos lineales eliminan variables o periodos de tiempo para ajustar los datos a los criterios de normalidad. En este proceso se puede eliminar información valiosa para determinar el comportamiento de las ventas.

La aportación de los métodos lineales es que dan la magnitud de las variables dependientes con las independientes, es decir, correlacionadas de manera positiva o negativa. También se resalta que la información de trimestres pasados tiene relevancia en el comportamiento de las ventas de las empresas: Bachoco, Bafar, Bimbo, Gruma, Lala y Maseca.

En este estudio se utilizaron las RNA como una herramienta para cuantificar el impacto de las variables propuestas en las ventas de siete empresas del sector alimentos (Bachoco, Bafar, Bimbo, Gruma, Herdez, Lala y Maseca) y destacar aquellas que presentaron un mayor impacto. Esta investigación coincide con Valdivia y Morales (2016) quienes a través del algoritmo de Garson midieron el impacto de seis variables económico-financieras (Dow Jones Industrial Average, Consumer Price Index, reservas internacionales, tasa de interés de cetes, agregado monetario 1 y tipo de cambio) en el comportamiento del índice de precios y cotizaciones mediante un modelo de RNA.

Morales y García (2016), utilizando una metodología de arquitectura de red neuronal optima de perceptrón multicapa, clasificaron y predijeron las empresas exitosas y no exitosas del sector comercial de la BMV. Primero determinaron la RNA óptima y después establecieron las razones financieras más importantes para determinar el desempeño de las empresas. En esta investigación se siguió la misma metodología para la construcción y evaluación de las arquitecturas de RNA propuestas obteniendo como la razón financiera más importante para determinar las ventas de las empresas del sector alimentos: pasivo total/activo total.

Chávez (2015) utilizando distintos algoritmos de clasificación de minería de datos (Native Bayes, ML Perceptrón, IBl, Bagging, Decision Table, BF Tree) para pronosticar la tendencia de los precios del tipo de cambio peso mexicano dólar concluye que las RNA muestran un mejor desempeño en comparación con los métodos tradicionales. Lo cual contrasta con esta investigación en donde los modelos de árbol de decisiones y tabla de decisiones tienen mejores resultados en comparación con RNA.

En esta investigación se tiene como hallazgos que los modelos de regresión lineal presentan mayor precisión en el pronóstico de ventas de seis de siete empresas del sector alimentos analizadas (Bachoco, Bafar, Bimbo, Herdez, Lala y Maseca) 
en comparación con los modelos de RNA. Esto contrasta con Villar (2013) quien concluye que las RNA superan otras metodologías como los métodos tradicionales de análisis de series de tiempo en los pronósticos aplicados al tipo de cambio.

Además, se encontró que las técnicas de minería de datos (tabla de decisiones y árbol de decisiones) pronosticaron las ventas de Bachoco, Bafar, Bimbo, Gruma, Herdez y Maseca con mayor precisión que los modelos de RNA y regresión lineal. Este descubrimiento contrasta con Melchor (2010) quien concluye que el uso de modelos basados en RNA para el pronóstico de la inflación presenta numerosas ventajas frente a otros métodos.

Se encontró que para el pronóstico de ventas de Gruma, los modelos de RNA constituyen una herramienta útil para el reconocimiento de patrones en periodos de crisis (2008-2009). Esta investigación coincide con Morel (2012) quien desarrolló modelos de RNA para el estudio de crisis bancarias en México de 1994 a 1995 y concluye que el uso de RNA es útil en el estudio de la economía mexicana en periodos de crisis.

También se cumple lo propuesto por García et al. (2009) en donde se plantea que, en ocasiones, los modelos más simples son los que pueden llegar a tener mejores resultados en comparación con los más complejos. Tal es el caso de los modelos econométricos que son comparados con el desempeño de las redes neuronales.

El modelo de ventas de la empresa Gruma basado en redes neuronales artificiales obtiene un mayor ajuste a los datos en comparación con los modelos de RNA de las otras seis empresas, esto debido a las siguientes características de la empresa: como estrategia de crecimiento, en el periodo del 2006 al 2015, Gruma adquirió y construyó doce plantas en Estados Unidos, Europa, Asia y Oceanía. Para lograr el crecimiento de largo plazo, Gruma utiliza estrategias de financiamiento: una a través del banco Banorte del cual tiene participación accionaria, y el otro través del financiamiento del mercado de valores al ingresar a la BMV y al New York Stock Exchange. El objetivo de expansión no está limitado a la generación de flujo de efectivo, por lo tanto, la estructura de capital toma relevancia en la expansión de la empresa.

De acuerdo con Huerta (2008), el consumo de maíz se ha reducido en los últimos años como resultado de cambios en los hábitos de consumo de la población que cada vez se concentra más en las ciudades. El aumento en el consumo de productos de harina de trigo ha sustituido el consumo de tortillas

Entre los principales hallazgos de esta investigación se encuentran:

Los modelos de regresión lineal pronostican con mayor precisión en el corto plazo que las RNA. Esto debido a que se tiene un histórico tendencial que permite 
que estos modelos lo tomen para pronosticar en los trimestres inmediatos y que esta tendencia se pierda en el largo plazo lo que supondría un mejor desempeño de los modelos no lineales.

La selección de las variables para la construcción del modelo de ventas depende de las decisiones financieras de la empresa que se quiera analizar. Estas se ven reflejadas en la compra o ausencia de coberturas sobre el tipo de cambio y el desempeño de las razones financieras.

Los modelos de árbol de decisiones y tabla de decisiones mostraron mejores resultados en el ajuste a los datos históricos de las ventas. Esto debido a que estas técnicas de minería de datos asignan categorías de una lista de decisiones o reglas de las variables independientes. Esto se asemeja a la repercusión que tienen las decisiones que toma una empresa en el incremento o disminución de sus ventas.

\section{BIBLIOGRAFÍA}

Chase, Charles (1997). Selecting the Appropriate Forecasting Method. En: The Journal of Business Forecasting and Systems, vol. 14, n. 3 , p. 23-29.

Chávez Sánchez, Carlos Omar (2015). Modelo de predicción de la tendencia del tipo de cambio peso-dólar mediante triangulación de arbitraje. Tesis para optar al título de Magíster en Finanzas. Maestría en Finanzas, Universidad Nacional Autónoma de México, Ciudad de México, 1-49.

Economática (2016). Plataforma [Base de datos]. Alicorp

García, Arturo; Vázquez, Daniel; Reyes, Heriberto; Sáenz, Alberto y Limón, Alejandro (2009). Investigación en el ámbito empresarial: pronósticos, supervisión e indicadores financieros (estudio de casos). Veracruz: Universidad Cristóbal Colón, 202 p.

Gupta, Saurabh y Kumar, Nishant (2013). A study of advancement in sales forecasting models. En: Pranjana, vol. 16, n. ${ }^{\circ}$ 1, p. 1-10.

Huerta, Rogelio (2008). Monopolio, precio de la tortilla y estancamiento de la economía mexicana. En: Economía Informal, vol. 351, n. ${ }^{\circ}$ 2, p. 67-84.

Inegi -Instituto Nacional de Estadística y Geografía. (2017). Indicadores de población. Recuperado de https://www.inegi.org.mx/temas/estructura/

Jain, Chaman (2002). Benchmarking the management support for a forecasting function. En: The Journal of Business Forecasting Methods and Systems, vol. 21, n. ${ }^{\circ}$ 3, p. 8-10.

Juárez Rodríguez, Viridiana. (2007). Análisis del efecto del tipo de cambio en la estructura financiera de las empresas que cotizan en la Bolsa Mexicana de Valores: sector alimentos, bebidas y tabaco. Tesis para optar al título de Licenciado. Licenciatura en Contaduría, Universidad Nacional Autónoma de México, Ciudad de México, 1-158. 
Lundberg, Johan y Lundberg, Sofia (2012). Distributional Effects of Lower Food Prices in a Rich Country. En: Journal of Consumer Policy, vol. 35, n. ${ }^{\circ}$ 3, p. 373-391.

Makridakis, Spyros y Wheelwright, Steven (1977). Forecasting: Issues and Challenges for Marketing Management. A framework from relating the available techniques to specific situations. En: Journal of Marketing, vol. 41, n. 4 , p. 24-38.

Melchor Quinto, Argelia (2010). Uso de redes neuronales artificiales para el pronóstico de la inflación. Tesis para optar al título de Licenciado. Licenciatura en Actuaría, Universidad Nacional Autónoma de México, Ciudad de México, 1-92.

Morales, Arturo y García, Oswaldo (2016). Clasificación y predicción de las empresas exitosas y no exitosas del sector comercial de la BMV mediante el uso de redes neuronales óptimas. En: Revista Administración de Riesgos, vol. 6, n. ${ }^{\circ}$ 1, p. 51-94.

Morel Salas, Graciela (2012). Predicción de crisis financieras utilizando redes neuronales artificiales: un ejercicio para la economía mexicana. Tesis para optar al título de Doctor. Doctorado en Economía, Universidad Nacional Autónoma de México, Ciudad de México, 1-235.

Ohidul, Haque (2005). Income Elasticity and Economic Development Methods and Applications. En: Advanced Studies in Theoretical and Applied Econometrics, vol. 42, n. ${ }^{\circ}$ 1, p. 111 122.

Standard E Poor's Dow Jones Indices (2017). SEP Dow Jones Indices. Recuperado de http://www. spdji.com

Valdivia, Stephanie y Morales, Arturo (2016). Determinants of the Index of Prices and Quotations on the Mexican Stock Exchange: Sensitivity Analysis Based on Artificial Neural Networks. En: Global Journal of Business Research, vol. 10, n. ${ }^{\circ}$ 2, p. 27-32.

Van Tassel, Charles (1967). Analysis of Food Demand. En: Journal of Retailing, vol. 43, n. ${ }^{2}$ 2, p. 38-43.

Villar Corona, Marco Antonio (2013). Pronóstico del tipo de cambio peso-dólar utilizando redes neuronales artificiales. Tesis para optar al título de Magíster en Finanzas. Maestría en Finanzas, Universidad Nacional Autónoma de México, Ciudad de México, 1-115.

Wienclaw, Ruth (2015). Forecasting Methods for Management. En: Research Starters -Business, p. 1-6.

Zhang, G. Peter. (2004). Neural Networks in Business Forecasting. USA:

Universidad del estado de Georgia. 